\title{
The emplacement of Voorspoed pipe, South Africa: a tale of incremental pipe growth, tephra jets, mixing, and a shallow crater
}

\author{
Alexandrina Fulop ${ }^{1}$, Stephan Kurszlaukis ${ }^{1}$, Ricardo Rodrigues ${ }^{2}$, Johann Stiefenhofer ${ }^{3}$ \\ 1. De Beers Canada; 300-1601 Airport Rd., Calgary, Alberta, T2E 6Z8; \\ Alexandrina.Fulop@debeersgroup.com; Stephan.Kurszlaukis@debeersgroup.com \\ 2. De Beers Consolidated Mines (Pty) Ltd; Voorspoed Mine; PO Box 1964, Kroonstad, 9500 \\ Ricardo.Rodrigues@debeersgroup.com \\ 3. MinRes, Corporate Division, Anglo American Operations Ltd, Johannesburg, South Africa; \\ Johann.Stiefenhofer@debeersgroup.com
}

\section{Introduction}

The Lower Cretaceous Voorspoed kimberlite pipe is one of the six pipes which comprise the Kroonstadt Kimberlite Cluster located in the central region of the Kaapvaal Craton (South Africa). The pipe was initially described as a typical South African tuffisitic kimberlite (Skinner, Marsh, 2004) and later on as a pipe with a $2 \mathrm{~km}$ deep crater filled by pyroclastic sedimentation and resedimentation of kimberlite and country rock debris (Howarth, Skinner, 2012) due to the presence of bedded volcaniclastics at a depth of $2 \mathrm{~km}$ from the original land surface.

In 2013-2014, a volcanological and petrological study was carried out at Voorspoed mine, following onsite detailed drill core logging and pit mapping. The distribution of the main rock types (Fig. 1) and their spatial relationships investigated in the open pit and drill core revealed a complex facies architecture reflecting a not less complex pipe growth history.

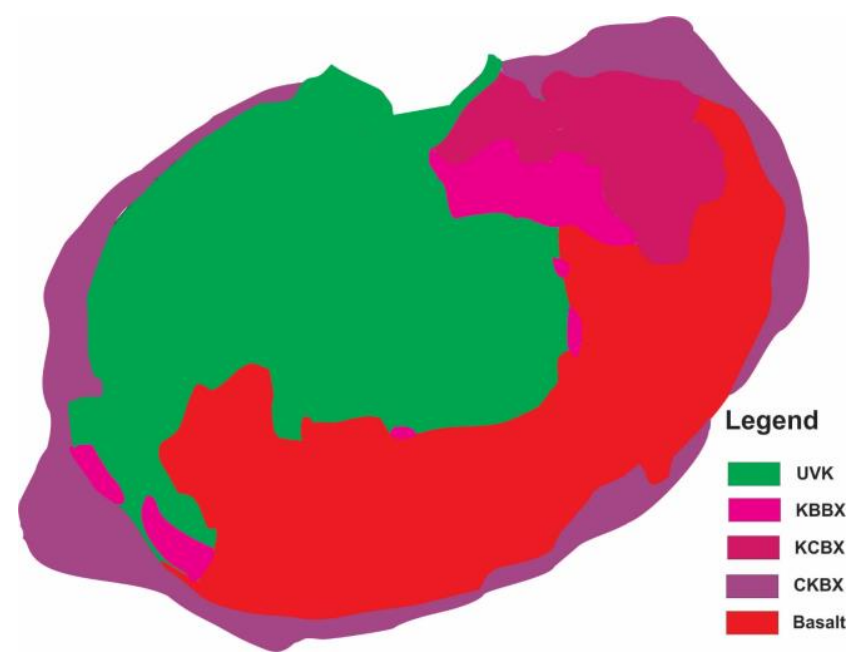

Figure 1: Map of the Voorspoed mine pit with the location of the main rock types

\section{Key findings}

Petrography and whole rock chemistry confirm the main volcaniclastic rock types previously identified in Voorspoed pipe: UVK, RXVK, OVK, KCBX and CKBX. Under the microscope, the rocks indicate mixing of different types and abundances of magmatic components (juvenile and cognate pyroclasts) 
and country rock xenoliths. Two main types of magmatic components are described in the Voorspoed volcaniclastics, their discrimination being based on olivine and phlogopite abundance ratios (Fig. 2a, b).
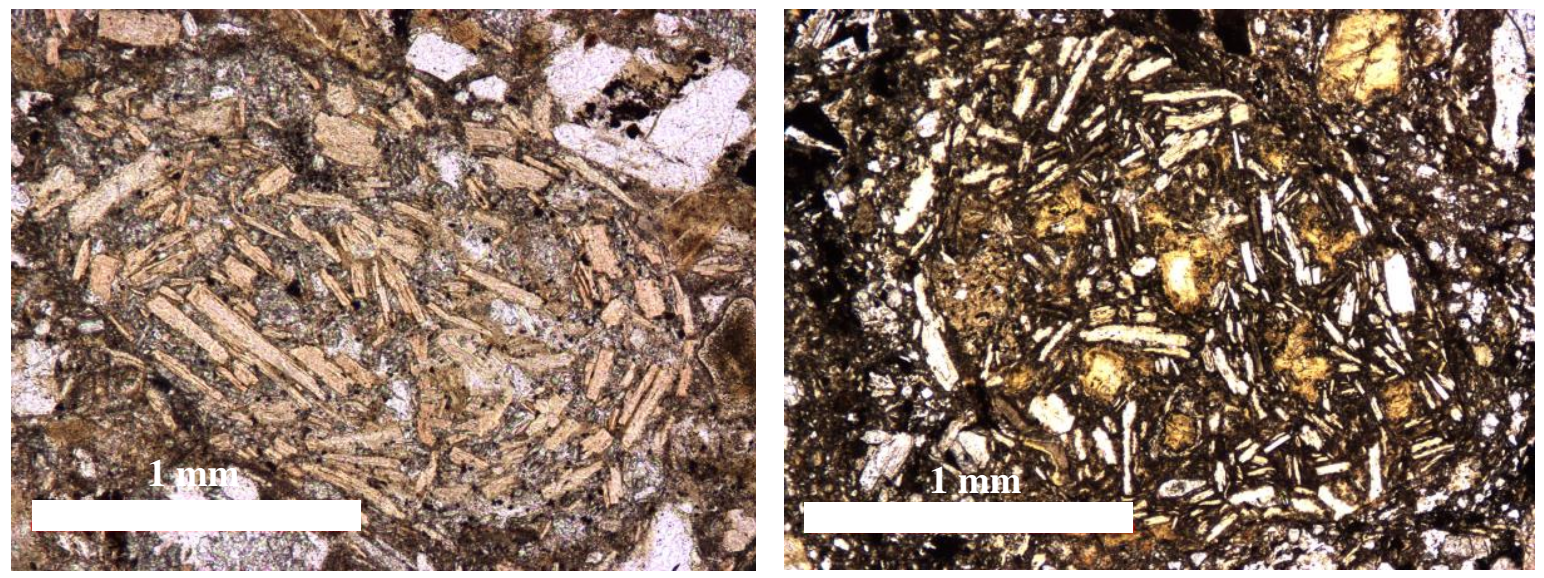

Figure 2: a) Type 1 juvenile pyroclast typical for UVK; b) type 2 juvenile pyroclast, typical for RXVK and OVK.

The type 1 magmatic components are defined by juvenile and cognate pyroclasts which are enriched in phlogopite compared to olivine, and are typically dominant in UVK (Fig. 2a). The type 2 magmatic components are defined by juvenile and cognate pyroclasts which are enriched in olivine compared to phlogopite, and are typically dominant in both RXVK and OVK (Fig. 2b). Although the predominance of magmatic components discriminates sometimes between the UVK and RXVK/ OVK samples, samples of UVK and RXVK/OVK which show similar abundances of type 1 and type 2 magmatic components cannot be discriminated based on this criterion alone. Hence, additional discriminants need to be used to separate the rock types, such as: the frequent presence of a certain type of country rock xenolith like basalt and dolerite, mudstone or black shale; the dominant phlogopite v. olivine component ratio in the matrix, which separates the UVK from the RXVK or OVK, and the grain size and abundance of magmatic components which separate the OVK from the RXVK.

The KBBX and CKBX are interpreted as the more diluted facies of UVK and RXVK. In general, the crustal contamination increases progressively from the OVK and RXVK to UVK, KBBX and CKBX. Whole rock chemistry data discriminate the UVK, RXVK, OVK, KBBX and CKBX rock types. The chemistry of the rock types is controlled by olivine and phlogopite abundance, as well as dilution type and abundance.

The UVK, RXVK and OVK are characterized as "typical" kimberlite varieties if they are dominated by magmatic components of either type 1 or 2 , respectively. These rock types commonly occur along the margins of the pipe. Towards the center of the pipe and at depth, the UVK, RXVK and OVK become progressively enriched in the alternating type of magmatic components. These rocks are classified as "hybrid" varieties, and are volumetrically much more abundant than the "typical" kimberlite varieties. The complex petrography suggests sequential eruptions of different magma batches, as indicated by texturally different types of juvenile pyroclasts that were often subsequently mixed and recycled, the latter testified by composite types. End member juvenile pyroclast textures can be traced in all model codes along the margins of the pipe, while the central part is characterized by mixing and recycling of a wide range of textures. This arrangement is best explained by the injection of tephra jets and the consequent collapse of their feeder conduits causing the thorough mixing of several singular and complex composite textured juvenile pyroclasts. In addition, the geometry of the different model codes and their spatial relationships suggest a combination of pyroclastic sedimentation and resedimentation. The UVK occupies the largest portion of the pipe and it is thickest in the central western area of the pipe (Fig. 1). RXVK/OVK is thickest in the NE and shows a wedge geometry which thins towards the SW (Fig. 1). In the central part of the pipe, RXVK/OVK is interlayered with UVK at depth. Pyroclastic sedimentation and resedimentation in the UVK from the central-western part of the pipe, interrupted by 
a RXVK/OVK resedimentation event from the NE towards the SW added complexity in the distribution of the different model codes.

The incremental pipe emplacement records several eruptive events separated by hiatuses and the presence of a constantly rather shallow crater. Root zone processes typically include explosive fragmentation but also non-explosive intrusion of magma and, during hiatuses, its consolidation and subsequent fragmentation in later eruptions, as testified by abundant cognate xenoliths with textures similar to the juvenile pyroclasts. Hiatuses are also characterized by passive crater widening through gravitational collapse of unstable crater walls and their overlying tephra rings. This is shown by abundant talus deposits with variable resedimented kimberlite/country rock debris ratio. The country rock componentry identified in the KBBX and CKBX talus deposits varies, and the prevalence of a certain lithology can be linked with a specific source area in the country rock stratigraphy exposed in the maar crater collar suggesting a step-wise crater widening in rather small events. Hiatuses in pyroclastic sedimentation are also implied by ashy mud layers with ductile deformation that suggest at least the temporary presence of a water body in the crater.

The widening of the crater in rather small-volume depositional events and their point source from specific basalt and shale strata suggest that the crater was rather shallow (probably only a few hundred meters). Such a shallow crater was maintained by tephra jets moving material from the root zone to the surface, deposition of pyroclastic and resedimented material onto the crater floor, and subsidence of the diatreme infill into the root zone. Strong evidence for this "conveyor-belt" recycling process can also be seen in Voorspoed pipe by abundant and well developed shear zones along the margin of the pipe.

\section{Conclusions}

Our investigation confirms and enhances the rock classification at the mine. Rock discrimination applying petrography tools like the visual estimation of olivine grain size and abundance in the magmatic components and matrix, as well as the identification and estimation of the abundance of country rock xenoliths in all model codes, and the pXRF analysis of blast pattern cuttings are tools that can be used to discriminate the rock types in the mine. The high complexity revealed by our study is reflected in grade distribution. The diamond distribution within the pipe is controlled by the emplacement of several magma batches in the form of feeder conduits, as well as primary pyroclastic and resedimented tephra deposits from the maar crater collar onto the crater floor. Cross-cutting tephra jets have homogenized, mixed and redistributed tephra and consequently the diamonds from preexisting deposits.

The understaning of emplacement processes is essential for the development of a robust geological model. In addition, grade information from LDD's correlated with pilot hole data, a systematic sampling protocol and quantitative, complementary data sets are critical to understand the grade distribution in a kimberlite pipe.

\section{References}

Howarth G.H., Skinner E.M. (2012) The geology and emplacement of the volcaniclastic infill at the Voorspoed Group II kimberlite (orangeite) pipe, Kroonstad Cluster, South Africa

J. Volcanol. Geoth. Res. 231-232: 24-38

Skinner E.M.W., Marsh J.S. (2004) Distinct kimberlite classes with contrasting eruption processes Lithos 76: 183-200 